\title{
A "guerra" contra o gênero: reações às últimas décadas de políticas de promoção da igualdade de gênero no Brasil*
}

Fernando de Figueiredo Balieiro**

Keila Deslandes ilumina aspectos cruciais da luta pelo reconhecimento das diferenças no que tange a gênero $e$ sexualidade nas políticas educacionais brasileiras das últimas décadas. Suas reflexões, em parte, são assentadas na participação direta da autora e professora como coordenadora do curso Gênero e Diversidade na Escola em sua modalidade oferecida pela Universidade Federal de Ouro Preto (UFOP). Deslandes destaca a importância do curso de formação de professores que surgiu, em sua primeira edição, de uma parceria da Secretaria de Políticas para Mulheres, o Ministério da Educação (MEC), o British Council e o Centro Latino-Americano de Sexualidade e Direitos Humanos (CLAM/UERJ).

Desde a primeira edição, com o suporte do MEC, são várias as universidades que oferecem o curso de aprimoramento voltado à formação continuada dos professores da rede pública, proporcionando um contato mais próximo entre universidade $e$ escola, além da elaboração de materiais didáticos variados em relação à temática. O próprio curso é tributário, como mostra a autora, de um longo caminho de definições legais no que tange à educação no Brasil, desde a promulgação da Constituição de

* Recebida em 5 de novembro de 2016 aceita em 28 de novembro de 2017. Resenha do livro DESLANDES, Keila. Formação de professores e Direitos Humanos: construindo escolas promotoras da igualdade. Belo Horizonte, Autêntica Editora; Ouro Preto-MG, UFOP, 2015.

** Professor Adjunto do Departamento e do Programa de Pós-Graduação em Ciências Sociais da Universidade Federal de Santa Maria (UFSM); pesquisador do Quereres - Núcleo de Pesquisa em Diferenças, Gênero e Sexualidade. fernandofbalieiro@gmail.com 
1988, passando pelos Parâmetros Curriculares Nacionais (PCNs) definidos em 1996 e, especialmente, pela consolidação da Secretaria de Educação Continuada, Alfabetização, Diversidade e Inclusão (SECADI), da Secretaria de Políticas para Mulheres (SPM) e também da Secretaria de Política de Promoção da Igualdade Racial (SEPPIR). Nesse sentido, Deslandes propõe a pergunta que motivou a escrita do livro: "afinal, após uma década de políticas de formação continuada de professores para as temáticas de gênero, estamos mais próximos de uma escola promotora da igualdade de gênero no Brasil?' (p. 85-86, grifo da autora).

$\mathrm{O}$ desenvolvimento de tais políticas, ainda que tímidas, pareciam sinalizar que estaríamos a avançar a passos largos em torno do reconhecimento das diferenças de gênero e sexualidade. No entanto, os últimos anos parecem ter mostrado a emergência de outros caminhos, com o inesperado recrudescimento do preconceito, da intolerância e da desinformação em relação a gênero e sexualidade. Não parece ser mera coincidência que a SECADI, a SPM e a SEPPIR perderam o status de Ministério logo após o processo de impeachment de Dilma Rousseff, sendo acoplados ao Ministério da Justiça ou da Educação. É possível afirmar, extrapolando a discussão do livro publicado ainda em 2015, que programas relativos às diferenças ou à diversidade, já bastante enfraquecidos e com oposição cada vez mais demarcada na sociedade brasileira, saíram dos objetivos políticos governamentais no novo governo de Michel Temer, mais alinhado com forças políticas regressivas.

Tais questões têm como pano de fundo o desenvolvimento de um intenso embate analisado por Keila Deslandes em Formação de professores e Direitos Humanos: construindo escolas promotoras da igualdade. A autora utilizou-se da metáfora da guerra, emprestada de Susan Sontag (2007), analisando a formação de dois exércitos: os "promotores" e os "combatentes" da igualdade de gênero. Nessa perspectiva, Deslandes se volta às disputas em torno da questão no Brasil contemporâneo, por meio da análise dos textos legais e projetos de lei que se fazem cada vez mais presentes no congresso brasileiro. 
Em um primeiro momento, Deslandes apresenta sucintamente a emergência do conceito de gênero e sua recepção nos meios acadêmicos brasileiros. Retoma a proposição de Simone de Beauvoir sobre o devir feminino, "ninguém nasce mulher, torna-se", abrindo a compreensão do pensar a mulher como uma construção ou sujeito da cultura. Tratava-se do início do rompimento teórico com concepções essencialistas que atribuía às feminilidades, $e$ (por que não?) masculinidades, determinações anatomobiológicas. A autora nos mostra que, a partir da incorporação de tal perspectiva, de uma área voltada aos estudos da mulher à gradual inserção do conceito de gênero, até a emergência de vertentes queer, instaura-se a possibilidade de pedagogias transformadoras no que diz respeito às experiências de gênero e sexualidade.

Analisando a inserção desses temas em projetos educacionais no Brasil, envolvendo acadêmicos, pós-graduandos, educadores e instituições acadêmicas, Deslandes buscou analisar as "recepções" desse conceito no contexto político atual, com o objetivo de "esboçar uma cartografia estratégica" (p. 31) das forças que se contrapõem no embate político-discursivo na ordem do dia das discussões sobre políticas educacionais. Para tanto, perfaz um percurso histórico curioso ao mostrar que a luta para atribuir relevância ao gênero nas políticas educacionais resultou não em um trajeto linear de progressiva incorporação da sociedade em relação à importância da temática em uma sociedade democrática. De forma tortuosa, o fortalecimento das áreas de pesquisa de gênero e das políticas públicas educacionais na temática se depararam com uma reação conservadora que traduz as demandas por reconhecimento, a partir de uma leitura enviesada, em uma ameaça às famílias, às crianças e, no limite, à sociedade. Tal polarização só pode ser compreendida historicamente, e é retomando tais questões na história recente do país que Deslandes nos permite desenrolar esse emaranhado novelo.

Apoiando-se em pesquisas de Cláudia Vianna (2006) e seus/suas colaboradores, Deslandes aborda a incorporação da 
dimensão de gênero nas políticas públicas e nos textos normativos que regem a Nova República. Assim, a autora se volta para a Constituição de 1988, para a Lei de Diretrizes e Bases (LDB) de 1996, para os PCNs de 1997 e para o Plano Nacional de Educação de 2001. A autora constata que embora o termo "gênero" não apareça na Constituição, uma gama de princípios que se baseiam na igualdade de gênero foi incorporada em seu texto, assinalando a emergência de leis protetivas e antidiscriminatórias, a proteção da mulher no mercado de trabalho, a assistência gratuita às crianças em creches, licença gestante, dentre outras, ressaltando o objetivo fundamental da República: "promover o bem de todos, sem preconceitos de origem, raça e sexo" (Art. $3^{\circ}$, IV).

A Lei de Diretrizes e Bases, por sua vez, formalizou-se como um documento "[...] bastante tímido ao discutir princípios de igualdade e "apreço à tolerância'" (p. 35) no que tange a gênero, ainda que não deixasse de mencionar a questão dos direitos humanos. Já na entrada do século XXI, o PNE foi sancionado sem constar menção às relações de gênero no centro de seus "objetivos e prioridades", ainda que abordasse a necessidade de se evitar a produção de estereótipos de gênero, colocasse gênero nas temáticas transversais de formação docente e explicitasse a preocupação pela coleta de informações relevantes para a formulação de políticas de gênero no Ensino Superior. Publicados anos antes, os PCNs, de 1997, dão maior ênfase ao gênero nos conteúdos escolares, oficializando o tema de gênero e sexualidade nas escolas e prenunciando uma série de desenvolvimentos pedagógicos em relação ao tema.

Até então, a abordagem de gênero esteve restrita à temática das desigualdades entre homens e mulheres:

O conceito de gênero nas políticas públicas educacionais brasileiras até o início do século XXI se restringiu objetivamente, portanto, ao tema da emancipação $e$ empoderamento da mulher, com seus múltiplos vieses de inserção feminina em face da sociedade patriarcal e da dominação masculina (p. 38). 
Concomitantemente, nacional e internacionalmente, observa-se a entrada na agenda pública dos temas sobre diversidade sexual, desde os anos 1980, associada às questões de HIV-AIDS no mundo, tendo como reflexo a elaboração de Diretrizes para uma Política Educacional em Sexualidade, articulando os Ministérios da Educação e da Cultura. A autora aborda o fortalecimento da temática de gênero e diversidade sexual com a criação da SECAD, que se transforma em $\mathrm{SECADI}^{1}$, passando pelos Plano Nacional de Políticas para as Mulheres de 2004, o Programa Brasil sem Homofobia, do mesmo ano, até chegar ao Plano Nacional de Educação de 2014, já no governo de Dilma Rousseff, incorporando propostas retiradas da Conferência Nacional de Educação (CONAE), de 2010.

Quanto mais se formalizava uma política de reconhecimento às diferenças, mais se esboçava uma reação conservadora. A criação do Programa Escola sem Homofobia, que previu a elaboração de material didático para combater a homofobia, sob supervisão da SECADI, da Global Alliance for LBGT Education, a Associação Brasileira de Lésbicas, Gays, Bissexuais, Travestis e Transexuais, foi um exemplo dessa reação. Sua implementação "[...] tornou-se catalisadora de diversas e poderosas forças de resistência ao que posteriormente passou a ser conhecido como a 'ideologia de gênero' na educação nacional" (p. 41). A elaboração do material, que consumiu cerca de dois milhões de reais aos cofres públicos (p. 50), não prosperou e não foi implementado, sendo vetado pela Presidência da República sob alegação de que seu conteúdo seria inadequado. Em reação contrária,

Apelidado pejorativamente de "kit gay", este material pedagógico de combate à homofobia no ambiente escolar tornou-se o alvo maior das críticas ao Programa Escola sem Homofobia, em especial, oriundas da chama "bancada evangélica" $e$ de parlamentares conservadores $e$

${ }^{1}$ Incorporando o termo Inclusão. 
ultraconservadores, entre os quais se destacaram os discursos inflamados e amplamente difundidos pela mídia e redes sociais do deputado Jair Bolsonaro (PP-RJ), os quais acusava, que o conteúdo do kit faria "apologia ao homossexualismo e à promiscuidade" (p. 50).

O programa de combate à homofobia foi compreendido em uma chave pejorativa, sem que seu conteúdo fosse amplamente conhecido, tornando-se alvo de questionamentos até na disputa política pela prefeitura de São Paulo ${ }^{2} \mathrm{O}$ acontecimento serviu de estopim para a consolidação de um discurso contrário às políticas de gênero, dando força para políticos conservadores que, afirmando-se contra tais projetos que visavam perverter menores para o "homossexualismo", passaram a ocupar espaços mais destacados na política brasileira. Constata-se a reeleição de Jair Bolsonaro para deputado, dessa vez como deputado mais bem votado do estado do Rio de Janeiro, passando a ocupar cargo de titular da Comissão de Direitos Humanos e Minorias (CDHM).

Com foco particular no deputado federal católico de Minas Gerais, Eros Biondini, Deslances aborda como, ao lado dele, inúmeros outros políticos da chamada "bancada evangélica" foram eleitos no mesmo pleito, com o objetivo de barrar qualquer iniciativa de políticas educacionais voltadas a gênero $e$ sexualidade, a partir de uma série de projetos de lei que estão a aguardar votação. Dentre eles, destaca-se o Estatuto da Família que prevê uma definição legal de família restrita a casais heterossexuais. É nesse momento que passa a circular a expressão, cada vez mais popular, "ideologia de gênero" no debate político, como parte de uma "contraofensiva" com o objetivo de combater uma suposta:

[...]invasão da "ideologia de gênero" no país: um projeto de linhagem marxista, que tem como objetivo desestruturar

2 O material foi utilizado pela campanha de José Serra, concorrente à prefeitura de São Paulo (2012), contra Fernando Haddad, também candidato a prefeito e Ministro da Educação na época da elaboração do programa. 
a família e tornar as pessoas manipuláveis com base na pulverização de suas identidades sexuais. Pior: que vem sendo implantada, pelo governo, nas escolas e, portanto, incide sobre a parcela mais vulnerável da população: crianças $e$ adolescentes subjugadas por professores impos(i)tores (p. 58).

A autora se debruça sobre o PL 2731, de autoria do deputado Eros Biondini, o qual prevê a proibição da "ideologia de gênero" na educação nacional, podendo a infração à lei acarretar em perda do cargo ao professor ou mesmo ser tipificada como crime de submeter criança ou adolescente sob autoridade a vexame $e$ constrangimento; prevê, ainda, que o não atendimento a essa lei pelos planos de educação estaduais impossibilite o repasse de recursos financeiros federais destinados à educação para o estado.

É nesse contexto que se faz a discussão sobre o Plano Nacional de Educação, o qual absorve muito das proposições democratizantes da CONAE 2014. A partir de então, o embate de perspectivas se faz cristalino, marcado pela polarização e pela assertividade. $\mathrm{O}$ que salta aos olhos é como a questão de gênero foi se tornando cada vez mais central, a ponto de tomar grande parte do tempo dos debates das políticas educacionais que vão muito além de sua especificidade, tal como PNE.

Deslandes nos mostra como, em novembro de 2015, o PL 2.731 é retirado de tramitação para ser apensado ao projeto de lei de autoria do deputado federal Pastor Feliciano, PL 3236, que, em seguida, foi também apensado ao PL 7180, de Erivelton Santana, como estratégia de fortalecer um bloco de projetos de lei, tornando mais célere sua votação. Terceiro deputado mais votado do maior colégio eleitoral do país, Feliciano chegou mesmo a presidir a Comissão de Direitos Humanos e Minorias da Câmara dos Deputados, em 2013, mantendo-se como membro titular dessa comissão após sair de sua presidência. Feliciano foi autor, no ano de 2015, de oito documentos que buscam alterar ou criminalizar qualquer iniciativa associada ao que chama de "ideologia de gênero". O parlamentar segue argumentos semelhantes aos já descritos acima, fazendo alusão à importação 
do "gênero" de teorias perniciosas, apoiadas por fundações internacionais, ainda colocando ênfase na obra Problemas de Gênero, de Judith Butler, como originária da "ideologia de gênero":

Considerada pseudocientífica e perniciosa, além de exótica e portanto sem qualquer vínculo com a cultura nacional, a "ideologia de gênero" é rechaçada como sendo totalitária e tendo como objetivo a pulverização da família e, daí, o estabelecimento de um caos social, onde os indivíduos seriam facilmente manipuláveis, posto que desprovidos de suas referências identitárias fundamentais, referentes à família e à sexualidade (p. 75).

O PL 7180, aglutinando os demais, pretende alterar a LDB, garantindo, nos termos do projeto de lei, conforme destaca Deslandes, o

respeito às convicções do aluno, de seus pais responsáveis, tendo os valores de ordem familiar precedência sobre a educação escolar nos aspectos relacionados à educação moral, sexual e religiosa, ficando vedada a transversalidade ou técnicas subliminares no ensino desses temas (p. 77).

A autora ressalta como tal mudança legal representaria uma afronta à laicidade do Estado.

Os reflexos do fortalecimento da fração opositora às políticas em prol da igualdade de gênero revelam-se mais evidentes ao final de 2015, conforme Keila Deslandes nos evidencia, com alguns acontecimentos: a retirada da recém-proposta da SECADI de um comitê de gênero de caráter consultivo para implementar, avaliar e monitorar as políticas públicas educacionais, além da ausência deliberada do termo "gênero" nos planos estaduais de educação (com algumas exceções, das quais se destacam os estados do Mato Grosso, Mato Grosso do Sul, Pará, Rondônia e Maranhão).

A guerra contra o gênero no Brasil, analisada de forma pioneira por Deslandes, continua em andamento, ganhando corpo 
e ressonância nos anos de 2016 e 2017, não sendo difícil prever um cenário desolador no ano eleitoral de 2018 no que tange aos discursos regressivos sobre gênero e sexualidade, especialmente considerando a forma como eles têm sido capitalizados politicamente. Retrospectivamente, vimos que a implementação de projetos que combatessem os preconceitos e discriminações ou promovessem a igualdade de gênero, iniciada nos anos 1990 no Brasil, ganhou ênfase nos governos petistas. No entanto, foi durante o governo de Dilma Rousseff que se recuou na consolidação de tais políticas, capitulando diante da "bancada evangélica" e também católica sob alegação governamental de que seria necessário manter a base de apoio do governo, em um difícil governo de coalizão. Tais forças políticas regressivas, já consolidadas, se tornaram mais e mais atuantes no cenário do Brasil pós-golpe, gerando uma série de ações de grupos diversos que extrapolaram o âmbito da oposição às políticas públicas, buscando intervir inclusive na liberdade de pensamento em relação ao tema, como perceptível na formação de abaixoassinado e manifestação contrária à vinda de Judith Butler ao Brasil em novembro de 2017.

O livro de Keila Deslandes nos permite ver com clareza os processos que formaram o dramático quadro atual no Brasil. Trata-se de leitura necessária àqueles que se interessam pela temática de gênero, direitos humanos e democracia em um momento no qual os direitos sexuais e de gênero se apresentam ameaçados, revelando-se reflexão obrigatória em um cenário no qual é imprescindível resistir. 